\title{
NOTE
}

\section{Dimeric Termination of Living Polystyrene in the Reaction with Benzyl Chloride $^{1}$}

\author{
Mikio TAKAKI, Ryuzo Asami, and Yoshiyasu KuWATA \\ Department of Synthetic Chemistry, Nagoya Institute of Technology, \\ Gokiso-cho, Showa-ku, Nagoya 466, Japan.
}

(Received October 12, 1978)

\begin{abstract}
KEY WORDS Dimeric Termination / Living Polystyrene / Benzyl Chloride / One-Electron Transfer /
\end{abstract}

The reaction of benzylic chloromethyl groups with living polystyrene has been extensively utilized as a coupling reaction for the preparation of well-defined polymers because of the high coupling reactivity of these groups. This coupling reaction, however, is known to involve a side reaction to some extent, as pointed out in the literature ${ }^{2-7}$ and in our previous paper. ${ }^{1 \mathrm{~b}}$ The clarification of the side reaction is important for preparing more well-defined polymers by the coupling reaction. In the course of the investigation of the side reaction by use of benzyl chloride as the model compound, we found out that the reaction of living polystyrene with benzyl chloride involves the dimeric termination of living polystyrene; this will be dealt with here.

\section{EXPERIMENTAL}

\section{Materials and Reaction}

Reagent grade benzyl chloride (purity $>99.5 \%$ gas chromatography (GLC) after rectification) was stirred with calcium hydride for $24 \mathrm{~h}$ on a vacuum line $\left(10^{-5} \mathrm{mmHg}\right)$ and further distilled in vacuo over the drying agent. Polystyryllithium (PSt-Li) and polystyrylpotassium (PSt-K) were prepared as described previously. ${ }^{8}$ Their number-average molecular weights were $2.23 \times 10^{4}$ and $2.39 \times 10^{4}$, respectively. The reaction apparatus and the experimental procedure were also described previously. ${ }^{8}$

\section{Analysis of Products}

The presence of bibenzyl in the reaction products was confirmed with an authentic sample and was determined by GLC by use of tetradecane as an internal standard. The polymers recovered from the reaction mixture were analyzed by use of a Toyo Soda high-speed liquid chromatograph Model HLC 802UR connected with two GHM columns (GPC; $2 \mathrm{ft} \times 2$, Toyo Soda). Tetrahydrofuran $(\mathrm{THF})$ was used as the eluent and the flow rate was $1 \mathrm{ml} / \mathrm{min}$. The extent of the dimeric termination of living polystyrene was determined by the equation:*

Extent of the dimeric termination of living polystyrene, $\%$

$$
=2\left[1-\left(\bar{M}_{n}\right)_{\mathrm{L}} /\left(\bar{M}_{n}\right)_{\mathrm{R}}\right] \times 100
$$

In the equation, $\left(\bar{M}_{n}\right)_{\mathrm{L}}$ and $\left(\bar{M}_{n}\right)_{\mathrm{R}}$ are the numberaverage molecular weights of the living polystyrene and the recovered polymer, respectively; they were determined as described previously. ${ }^{8}$

\section{RESULTS AND DISCUSSION}

Figure 1 shows the GPC curves of PSt-Li protonated with methanol and the polymers recovered after the reactions of K-1, L-1, and L-3 in Table I. The peak of the protonated PSt-Li is very sharp and symmetrical. Its elution count was in close agreement with the count which was obtained from the

* Derived from the equation (proposed as eq 1 in Polym. $J .$, 9, 635 (1977) but unfortunately miswritten)

$$
\frac{n_{\mathrm{A}}}{N_{\mathrm{A}}}=\left\{1+v-\frac{\left(\bar{M}_{n}\right)_{\mathrm{A}}+\left(\bar{M}_{n}\right)_{\mathrm{B}} v}{\left(\bar{M}_{n}\right)_{\mathrm{R}}}\right\} f \quad \text { (correct) }
$$

where $v=1,\left(\bar{M}_{n}\right)_{\mathrm{A}}=\left(\bar{M}_{n}\right)_{\mathrm{B}}=\left(\bar{M}_{n}\right)_{\mathrm{L}}$, and $f=1$ in the reaction systems of this study. 


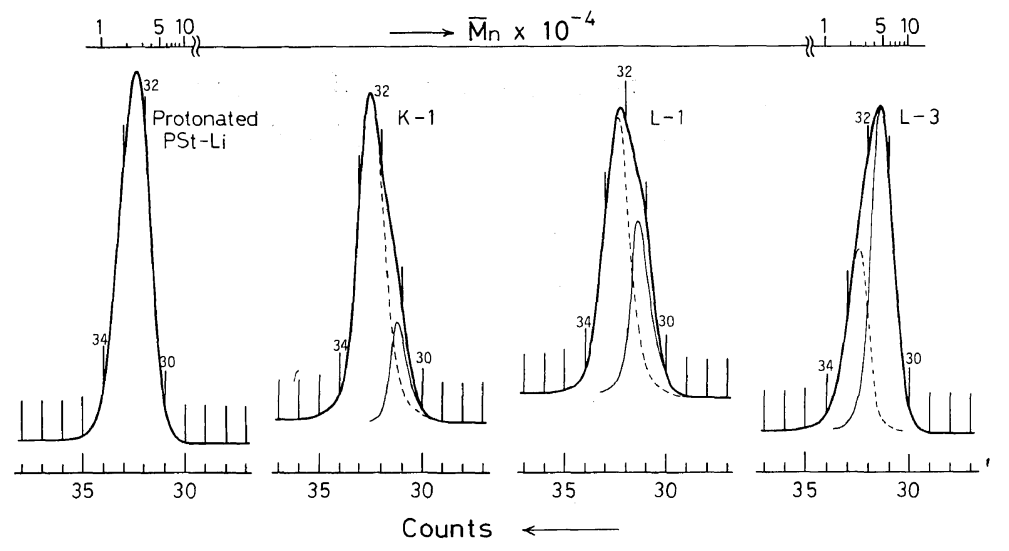

Figure 1. GPC curves of PSt-Li protonated with methanol and the polymers obtained in K-1, L-1, and L-3.

number-average molecular weight of PSt-Li by using the calibration curve of the appropriate column. However, the peak of the polymer obtained in L-1 is somewhat broad and bimodal. The peak of the polymer in L-3 was also shifted to 31.6 counts, which corresponds to twice the molecular weight of PSt-Li. These facts indicate that the dimeric termination of PSt-Li is taking place along with the nucleophilic substitution of PSt-Li with benzyl chloride. The extents of dimeric termination of living polystyrene in typical conditions are tabulated in Table I together with the extent of the conversion of benzyl chloride into bibenzyl. When the counterion of a polystyryl anion was $\mathrm{K}^{+}$, the extent of the dimeric termination of polystyryl anions was about $10 \%$ and the amount of bibenzyl formed was a few percent. In the case of

Table I. Dimeric termination of living polystyrene in the reaction with benzyl chloride ${ }^{a}$

\begin{tabular}{|c|c|c|c|c|c|c|c|c|c|}
\hline \multirow{3}{*}{ Expt } & \multirow{3}{*}{$\begin{array}{l}\text { Living PSt } \\
\text { [LE], } \\
\mathrm{mmol} / \mathrm{l}\end{array}$} & \multirow{3}{*}{$\begin{array}{c}\mathrm{PhCH}_{2} \mathrm{Cl} \\
{\left[\mathrm{CH}_{2} \mathrm{Cl}\right],{ }^{\mathrm{c}}} \\
\mathrm{mmol} / \mathrm{l}\end{array}$} & \multirow{3}{*}[\mathrm{CH}_{2}\mathrm{Cl}]{$/[\mathrm{LE}]$} & \multirow{3}{*}{ Solvent } & \multirow{3}{*}[\mathrm{THF}]{$/[\mathrm{LE}]$} & \multirow{3}{*}{$\begin{array}{c}\left(\bar{M}_{n}\right)_{\mathrm{R}}{ }^{\mathrm{d}} \\
\times 10^{-4}\end{array}$} & \multicolumn{3}{|c|}{ Products, $\%$} \\
\hline & & & & & & & \multicolumn{2}{|c|}{ PSt-PSt } & \multirow[b]{2}{*}{$\mathrm{BB}^{\mathrm{g}}$} \\
\hline & & & & & & & $\mathrm{Eq}^{\mathrm{e}}$ & $\mathrm{GPC}^{\mathrm{f}}$ & \\
\hline & PSt-Li & & & & & & & & \\
\hline L-1 & 4.36 & 4.36 & 1.00 & Benzene & 0 & 2.76 & 38 & 37 & 24 \\
\hline L-2 & 4.98 & 5.00 & 1.00 & Benzene & 0 & 2.72 & 36 & 32 & 28 \\
\hline L-3 & 3.24 & 3.31 & 1.02 & THF/Benzene ${ }^{\text {h }}$ & 19.6 & 3.16 & 59 & 58 & 50 \\
\hline \multirow[t]{2}{*}{ L-4 } & 4.41 & 4.50 & 1.02 & THF/Benzene ${ }^{\text {h }}$ & 821 & 2.25 & 2 & - & 2 \\
\hline & PSt-K & & & & & & & & \\
\hline $\mathrm{K}-1$ & 4.25 & 4.27 & 1.00 & THF & - & 2.53 & 11 & 14 & 6 \\
\hline $\mathrm{K}-2$ & 4.28 & 4.84 & 1.13 & THF & - & 2.48 & 7 & 15 & 1 \\
\hline
\end{tabular}

a The solutions of the reactants were mixed completely within a few seconds, as described previously, and the reaction mixture was permitted to stand for $8 \mathrm{~h}$ at $23^{\circ} \mathrm{C}$, although the yellow and the red color ascribed to PSt-Li and PSt-K, respectively, disappeared within $1 \mathrm{~h}$.

b Concentrations of living ends.

c Concentrations of chloromethyl groups.

d Number-average molecular weight of recovered polymer after the reaction.

e Extent of the dimeric termination of living polystyrene which was calculated from eq 1 .

${ }^{f}$ Extent of the dimeric termination estimated by GPC.

$\mathrm{g}$ Extent of the conversion of benzyl chloride into bibenzyl.

${ }^{\mathrm{h}}$ Mixture of benzene and THF. 
Dimeric Termination of Living Polystyrene

Table II. Influence of the order of addition of the reactants on the reaction of PSt-Li with benzyl chloride ${ }^{\mathrm{a}}$

\begin{tabular}{|c|c|c|c|c|c|c|c|}
\hline \multirow{3}{*}{$\begin{array}{l}\text { Order of } \\
\text { addition }^{b}\end{array}$} & \multirow{3}{*}{$\begin{array}{l}\text { PSt-Li } \\
\text { [LE], } \\
\mathrm{mmol} / \mathrm{l}\end{array}$} & \multirow{3}{*}{$\begin{array}{c}\mathrm{PhCH}_{2} \mathrm{Cl} \\
{\left[\mathrm{CH}_{2} \mathrm{Cl}\right]} \\
\mathrm{mmol} / \mathrm{l}\end{array}$} & \multirow{3}{*}[\mathrm{CH}_{2}\mathrm{Cl}]{$/[\mathrm{LE}]$} & \multirow{3}{*}{$\begin{array}{l}\left(\bar{M}_{n}\right)_{\mathrm{R}} \\
\times 10^{-4}\end{array}$} & \multicolumn{3}{|c|}{ Products, $\%$} \\
\hline & & & & & \multicolumn{2}{|c|}{ PSt-PSt } & \multirow[b]{2}{*}{ BB } \\
\hline & & & & & $\mathrm{Eq}$ & GPC & \\
\hline \multirow{2}{*}{ PSt-Li into $\mathrm{PhCH}_{2} \mathrm{Cl}$} & 4.30 & 4.49 & 1.04 & 2.78 & 40 & 38 & 24 \\
\hline & 3.26 & 6.68 & 2.11 & 2.73 & 37 & 33 & 18 \\
\hline \multirow{2}{*}{$\mathrm{PhCH}_{2} \mathrm{Cl}$ into PSt-Li } & 4.32 & 4.43 & 1.03 & 2.81 & 41 & 41 & 36 \\
\hline & 4.97 & 5.03 & 1.01 & 2.79 & 40 & 38 & 40 \\
\hline
\end{tabular}

${ }^{a}$ Reaction temperature, $23^{\circ} \mathrm{C}$; solvent, benzene.

b One reactant solution was added dropwise into the other over a period of about $8 \mathrm{~h}$.

$\mathrm{Li}^{+}$, the extent of the dimeric termination was $c a$. $37 \%$ in benzene solution, but it increased to $59 \%$ when a minute amount of THF (THF $\left.=0.52 \mathrm{vol}^{\%} \%\right)$ was added to the benzene solution. This amount was enough to affect the living-end behavior, since the molar ratio of THF to living ends is as high as 19.6. The extent of dimeric termination decreased to as low as $2 \%$ when the amount of THF was increased up to $29.4 \mathrm{vol} \%$. These effects of THF are in accord with those of THF on the extent of coupling reaction of PSt-Li with poly(chloromethylstyrene). ${ }^{1 \mathrm{~b}}$ Thus, in the case of the reaction of PSt-Li with benzyl chloride, the low extent of the dimeric termination suggests the high extent of coupling reaction of PSt$\mathrm{Li}$ with benzyl chloride. In the case of PSt-K, however, the low extent of the termination does not always indicate the high extent of coupling reaction in the $\mathrm{H}$-abstraction of a benzylic hydrogen by a PStK. ${ }^{9}$

As the reaction which gives the dimericterminated living polystyrene, a metal-halogen exchange can be considered, since this exchange reaction has always been regarded as the side reaction in the coupling reaction of living polystyrene with benzylic chloromethyl groups. ${ }^{2-7}$ To confirm this possibility, we investigated the influence of the order of addition of the reactants on both the extent of the dimeric termination of PSt-Li and the extent of the conversion of benzyl chloride into bibenzyl. If the dimeric termination proceeds through the pathway of metal-halogen exchange, the very slow addition of a benzyl chloride solution into a PSt-Li solution would be favorable for the dimeric termination. The polystyryl anions must be overwhelmingly present in much larger numbers than the resulting benzyl anions which can react with the polystyryl chloride formed by the exchange reaction. The addition of PSt-Li into benzyl chloride, on the other hand, would be favorable for the bibenzyl-forming reaction. The experimental results are not in accord with these expectations, as shown in Table II. The extent of the dimeric termination was found to be independent of the order of addition within the experimental error, and the extent of formation of bibenzyl was rather greater in the case of the addition of benzyl chloride into PSt-Li than in the reverse case. These results indicate the improbability of the metal-halogen exchange. This improbability is further supported by the fact that the dimeric termination takes place even in the reaction ${ }^{10}$ of living polystyrene with benzylic fluoromethyl groups, where fluorine atoms would not undergo the metal-halogen exchange at all. ${ }^{11}$ Thus, the dimeric termination does not proceed via metal-halogen exchange.

Although evidence has not been obtained, we suggest that one of the most probable courses of the dimeric termination in this study is one-electron transfer. Halasa and Adams ${ }^{12}$ suggested a oneelectron transfer mechanism in the similar reaction of living polybutadiene with alkyl chloride. Lichards $^{13}$ also claimed that the reaction of PSt-Li with triphenylmethyl bromide proceeds via the same mechanism. Further investigation is being undertaken to establish the existence of the one-electron transfer mechanism in the reaction of living polystyrene with benzyl halides. 


\section{REFERENCES}

1. (a) Preparation of Well-Defined Polymers by Polymer-Coupling Reaction. Part IV. (b) Part III: M. Takaki, R. Asami, and M. Ichikawa, Macromolecules, 10, 850 (1977).

2. T. Altares, D. P. Wyman, V. R. Allen, and K. Meyersen, J. Polym. Sci., Part A, 3, 4131 (1965).

3. S.-P. S. Yen, Makromol. Chem., 81, 152 (1965).

4. T. Fujimoto, H. Narukawa, and M. Nagasawa, Macromolecules, 3, 57 (1970).

5. J. C. Meunier and R. Van Leemput, Makromol. Chem., 142, 1 (1971).
6. F. Candau and E. Franta, Makromol. Chem., 149, 41 (1971).

7. J. Pannel, Polymer, 12, 558 (1971).

8. M. Takaki, R. Asami, and M. Mizuno, Macromolecules, 10, 845 (1977).

9. M. Takaki, R. Asami, and Y. Kuwata, submitted for publication in Macromolecules.

10. M. Takaki, R. Asami, H. Inukai, and T. Inenaga, submitted for publication in Macromolecules.

11. R. G. Jones and H. Gilman, Org. React., 6, 339 (1951).

12. A. F. Halasa and H. E. Adams, J. Polym. Sci., Polym. Symp., No. 30, 169 (1970).

13. D. H. Lichards, Chem. Commun., 322 (1968). 